\title{
Qualidade nutricional de cenoura e alface cultivadas em Mossoró-RN em função da densidade populacional
}

\author{
Francisco Bezerra Neto; Aurélio P Barros Júnior; Ebenézer de O Silva; Maria Z de Negreiros, Eliane Q \\ de Oliveira; Lindomar Maria da Silveira; Maria José T Câmara; Glauber Henrique de S Nunes \\ UFERSA, C. Postal 137, 59625-900 Mossoró-RN; E-mail: bezerra@ufersa.edu.br
}

\section{RESUMO}

O experimento foi realizado durante o período de junho a setembro de 2003, na área experimental do departamento de Ciências Vegetais da Universidade Federal Rural do Semi-Árido (UFERSA), em Mossoró-RN, com o objetivo de avaliar o efeito de densidades populacionais de cenoura e de alface, em segundo, cultivo na qualidade nutricional desses cultivos em sistema de consorciação em faixa. O delineamento experimental utilizado foi o de blocos casualizados, com os tratamentos arranjados em esquema fatorial 4 x 4, com três repetições. As populações de referência para o cultivo solteiro (PRCS) foram de 500.000 plantas.ha $^{-1}$ para a cenoura e de 250.000 plantas.ha $^{-1}$ para a alface, que corresponderam à densidade populacional de $100 \%$. Os tratamentos foram resultantes da combinação de quatro populações de cenoura $(40 \%, 60 \%, 80 \%$ e $100 \%$ da PRCS) com quatro populações de alface $(40 \%, 60 \%, 80 \%$ e $100 \%$ da PRCS). As características avaliadas nas raízes da cenoura foram firmeza, conteúdo de vitamina $\mathrm{C}$, carotenóides totais e beta-caroteno, e nas folhas da alface firmeza, conteúdo de vitamina $\mathrm{C}$, carotenóides totais e clorofila total. Foram utilizadas a cv Brasília (cenoura) e a cv. Tainá (alface). As associações de densidades populacionais de cenoura e alface não afetaram qualquer característica de ambas as culturas. Porém, as densidades populacionais da cenoura influenciaram as características da cenoura, e as densidades de alface afetaram as características da folha de alface. A firmeza, conteúdo de vitamina $\mathrm{C}$ e de beta-caroteno nas raízes da cenoura diminuíram com o aumento da densidade deste cultivo, enquanto que o conteúdo de carotenóides totais aumentou com o incremento na densidade populacional desta cultura. Mesmo comportamento decrescente também foi observado no conteúdo de vitamina $\mathrm{C}$, carotenóides totais e de clorofila total nas folhas de alface com o aumento da densidade populacional de alface.

Palavras-chave: Daucus carota, Lactuca sativa, composição química, consorciação.

\begin{abstract}
Nutritional quality of carrot and lettuce grown in MossoróRN, Brazil, as affected by plant densities
\end{abstract}

The experiment was carried out from June to September of 2003, in the experimental area of "Universidade Federal Rural do SemiÁrido" (UFERSA), in Mossoró, Rio Grande do Norte state, Brazil, in order to evaluate the effect of carrot and lettuce populational densities in a second growing period on their nutritional quality in a strip-intercropping system. A randomized complete block design was used with the treatments arranged in a $4 \times 4$ factorial scheme with three replications. The treatments consisted of the combination of four carrot-plant densities $(40 \%, 60 \%, 80 \%$ and $100 \%$ of the recommended sole crop density - RSCD) with four lettuce-plant densities $(40 \%, 60 \%, 80 \%$ and $100 \%$ of the RSCD). The reference populations for carrot and lettuce in sole crop, corresponding to $100 \%$, were of 500,000 plants.ha ${ }^{-1}$ and 250,000 plants.ha ${ }^{-1}$, respectively. Carrot cv. Brasília and lettuce cv. Tainá were planted. Quality characteristics evaluated were firmness and content of vitamin $\mathrm{C}$, total carotenoids and beta-carotene for carrot roots and firmness, contents of vitamin $\mathrm{C}$, total carotenoids and total chlorophyll for lettuce leaves. The associations of plant densities of carrot and lettuce did not affect any of the assessed characteristics in both crops. However, both carrot and lettuce plant densities affected the traits evaluated in both crops. The firmness, contents of vitamin $\mathrm{C}$ and beta-carotene in carrot roots decreased as the plant densities of carrot increased, while the content of total carotenoids increased as carrot population increased. The same decreasing behavior was observed in contents of vitamin $\mathrm{C}$, total carotenoids and chlorophyll in the lettuce leaves with an increase in the plant densities of lettuce.

Keywords: Daucus carota, Lactuca sativa, chemical composition, intercropping system.

\section{(Recebido para publicação em 3 de outubro de 2006; aceito em 18 de dezembro de 2006)}

\begin{abstract}
$\mathrm{A}$ cenoura e a alface são duas hortaliças bastante usadas na alimentação humana, com elevado valor nutricional (Mangels et al., 1993; Collins, 2004), que têm sido cultivadas em consorciação com algumas vantagens agroeconômicas e ambientais (Oliveira et. al., 2003). Um dos questionamentos que tem sido feito é se a utilização desta prática, quando submetida a diferentes densidades populacionais, destas hortaliças pode afetar a qualidade nutricional das culturas componentes.
\end{abstract}

Os fitoquímicos alfa-caroteno e beta-caroteno são os principais carotenóides encontrados na cenoura (Simon \& Wolff, 1987), além das vitaminas B, C, D e E e uma extraordinária fibra, chamada pectato de cálcio, que atua na diminuição da taxa de colesterol (WORLD CARROT MUSEUM, 2004). As folhas de alface são ricas em folato e contêm uma quantidade útil de betacaroteno, além de vitamina $\mathrm{C}$, potássio e certos fitoquímicos, como os flavonóides e lactucina (Collins, 2004).
A composição química das folhas de alface e da raiz de cenoura é variável e influenciada por fatores genéticos (Baardseth et al., 1995) e pelas condições de cultivo, tais como sistema de produção, tipo e propriedades físicas do solo, data de plantio, temperatura durante a estação de crescimento da cultura e período de crescimento entre outros (Mazza, 1989; Machado et al., 2003).

A cultivar de cenoura usada foi a Brasília, indicada para a região nordeste (Vieira et al.,1983). Ela apresenta fo- 
lhagem verde escura, raízes cilíndricas com coloração laranja-clara e baixa incidência de ombro verde ou roxo, resistência ao calor, à requeima por Alternaria e ao pendoamento prematuro. A cultivar de alface utilizada foi a Tainá, tipo americana (repolhuda crespa), indicada para o mercado de consumo in natura, devido ao excelente sabor. Caracterizase pela alta capacidade produtiva, tamanho grande de cabeça e alta resistência ao pendoamento precoce (SEMENTES SAKAMA, 2002).

Existem na literatura referências quanto ao efeito da densidade de plantio sobre a produção de fitoquímicos em cultivos solteiros de hortaliças. Carvalho et al. (2003) verificaram que os teores de carotenóides totais das cultivares de cenoura Nantes e Alvorada, em cultivo solteiro, não foi afetado pela densidade de plantas. Por outro lado, não foram encontrados trabalhos que avaliaram o teor de fitoquímicos em hortaliças, sob efeito de diferentes densidades populacionais em culturas consorciadas. Neste sentido, objetivou-se avaliar o efeito de diferentes densidades populacionais de cenoura e alface em segundo cultivo na qualidade nutricional destas culturas cultivadas em consórcio do tipo faixa.

\section{MATERIAL E MÉTODOS}

O experimento foi realizado na horta experimental da Universidade Federal Rural do Semi-Árido (UFERSA), em Mossoró-RN, de junho a setembro de 2003, em um Argissolo Vermelho Amarelo Eutrófico. As características do solo da área experimental foram: $\mathrm{pH}$ (água $1: 2,5)=8,49 ; \mathrm{Ca}=7,12 \mathrm{cmol}_{\mathrm{c}} \mathrm{dm}^{-3} ; \mathrm{Mg}=$ $4,48 \mathrm{cmol}_{\mathrm{c}} \mathrm{dm}^{-3} ; \mathrm{K}=1,64 \mathrm{cmol}_{\mathrm{c}} \mathrm{dm}^{-3}$; $\mathrm{Na}=0,24 \mathrm{cmol}_{\mathrm{c}} \mathrm{dm}^{-3} ; \mathrm{Al}=0,00 \mathrm{cmol}_{\mathrm{c}}$ $\mathrm{dm}^{-3}$ e $\mathrm{P}=382,7 \mathrm{mg} \mathrm{dm}^{-3}$.

$\mathrm{O}$ delineamento experimental utilizado foi o de blocos casualizados completos com três repetições, sendo os tratamentos arranjados em esquema fatorial $4 \times 4$. Os tratamentos consistiram da combinação de quatro populações de plantas de cenoura $(40 \%, 60 \%, 80 \%$ e $100 \%$ ) com quatro populações de plantas de alface $(40 \%, 60 \%, 80 \%$ e $100 \%)$. As populações de referência para o cultivo solteiro (PRCS) foram de 500.000 plantas.ha ${ }^{-1}$ para a cenoura (Siqueira, 1995) e de 250.000 plantas.ha $^{-1}$ para a alface (Silva, 1999), que corresponderam à densidade populacional de $100 \%$. Cada parcela, com área total de 3,84 m² (3,20 m x 1,20 m) continha cenoura e alface, cada uma ocupando metade da área em consórcio em faixas. As hortaliças foram plantadas em canteiros, contendo quatro fileiras, espaçadas entre si em 0,20 m. Para alface, os espaçamentos entre plantas foram de 0,$250 ; 0,166 ; 0,120$ e 0,100 $\mathrm{m}$, enquanto para cenoura foram de 0,125; 0,080; 0,060 e 0,050 m. A área útil da parcela foi de $1,60 \mathrm{~m}^{2}(1,60 \mathrm{~m} \mathrm{x}$ $1,00 \mathrm{~m})$. A bordadura constituiu-se das quatro fileiras de plantas localizadas nas laterais da parcela útil.

Antes da instalação do experimento em campo, foi realizada a solarização na área de plantio, durante 60 dias, cuja finalidade foi reduzir a população de fitopatógenos do solo, que viessem a prejudicar a qualidade das raízes de cenoura. Foram efetuadas capinas manuais e irrigação pelo sistema de micro-aspersão, duas vezes ao dia, proporcionando uma lâmina de irrigação entre 7 e 8 mm $\mathrm{dia}^{-1}$.

Em pré-plantio, aplicou-se 80 t.ha $^{-1}$ de esterco bovino, $40 \mathrm{~kg} \cdot \mathrm{ha}^{-1}$ de nitrogênio, na forma de uréia, e $30 \mathrm{~kg} \cdot \mathrm{ha}^{-1} \mathrm{de}$ $\mathrm{K}_{2} \mathrm{O}$, na forma de cloreto de potássio, de acordo com a análise do solo e recomendações da Empresa Pernambucana de Pesquisa Agropecuária (IPA, 1998). Foi realizada uma adubação nitrogenada em cobertura na alface, aos 15 dias após o transplantio, com 40 kg.ha- ${ }^{-1}$ de nitrogênio na forma de uréia. Na cenoura, foram realizadas duas adubações nitrogenadas, sendo a primeira aos 25 dias após o plantio e a segunda aos 45 dias, com $40 \mathrm{~kg} \cdot$ ha $^{-1}$ de nitrogênio na forma de uréia. Junto à primeira cobertura nitrogenada, aplicou-se $30 \mathrm{~kg} \cdot \mathrm{ha}^{-1}$ de $\mathrm{K}_{2} \mathrm{O}$, na forma de cloreto de potássio.

A cenoura, cultura principal foi semeada em 12 de junho de 2003 e o desbaste realizado 25 dias após a semeadura. Foram realizados dois cultivos sucessivos da alface em consórcio com a cenoura. Para isso, as mudas foram preparadas com semeaduras, em 30/06 e 08/08/2003, em copos descartáveis de $150 \mathrm{~mL}$, contendo como substrato co- mercial uma mistura de fibra de coco e composto orgânico na proporção de 1:2. Foram semeadas de três a cinco sementes por recipiente e aos três dias após a germinação efetuou-se o primeiro desbaste, deixando-se duas plântulas por recipiente, e aos oito dias o segundo desbaste, deixando-se apenas uma plântula por recipiente. As mudas foram produzidas sob sombreamento, utilizando-se uma estufa coberta com plástico branco. As mudas de alface do primeiro cultivo foram transplantadas para as áreas adjacentes às da cenoura, aos 24 dias após a semeadura e as do segundo cultivo aos 18 dias após a semeadura, quando a cenoura encontrava-se com 11 e 75 dias, respectivamente.

A colheita da cenoura foi realizada em 08 de setembro de 2003, perfazendo um ciclo de 88 dias após o plantio. A colheita da alface no primeiro cultivo foi realizada nos dias 21 e 22/07/2003, estando a cultura da cenoura aos 39 dias do plantio e alface aos 52 e 53 dias da semeadura. No segundo cultivo, a colheita foi realizada nos dias 18 e 19/09/2003, aos 41 e 42 dias após a semeadura.

As características nas folhas de alface foram avaliadas apenas no segundo cultivo, com o intuito de se evitar a possibilidade de uma interação entre os níveis dos fatores estudados na qualidade nutricional de ambos os cultivos. Foram avaliadas as seguintes características: firmeza (duas partes opostas do limbo foliar), conteúdo de vitamina $\mathrm{C}$, carotenóides totais e clorofila total. $\mathrm{Na}$ raiz de cenoura foram avaliadas firmeza (regiões opostas, ao longo da área mediana da raiz), conteúdo de vitamina C, carotenóides totais e $B$-caroteno. A firmeza foi avaliada por meio de penetrômetro digital computadorizado da marca Stable Micro Systems, modelo TA.XT2i, com sonda de $2 \mathrm{~mm}$ de ponta, e expressa em Newton $(\mathrm{N})$.

Os teores de vitamina $\mathrm{C}$ total foram quantificados segundo a metodologia proposta pela American Official Analysis of Chemistry - AOAC (39.051). Os conteúdos de clorofila total e carotenóides totais foram mensurados, no mesmo extrato vegetal, obtido a partir de $20 \mathrm{~g}$ do produto, utilizando-se a metodologia proposta por Lichtenthaler (1987), enquanto que o ß- 


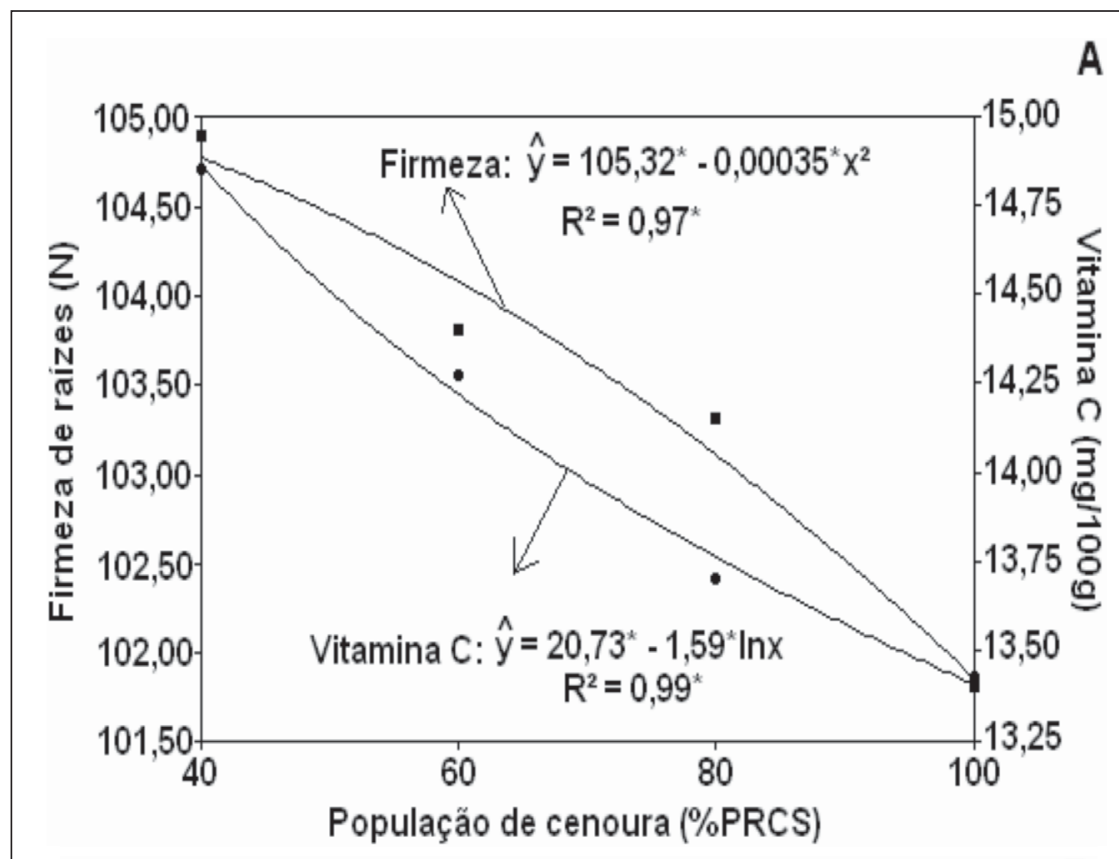

B

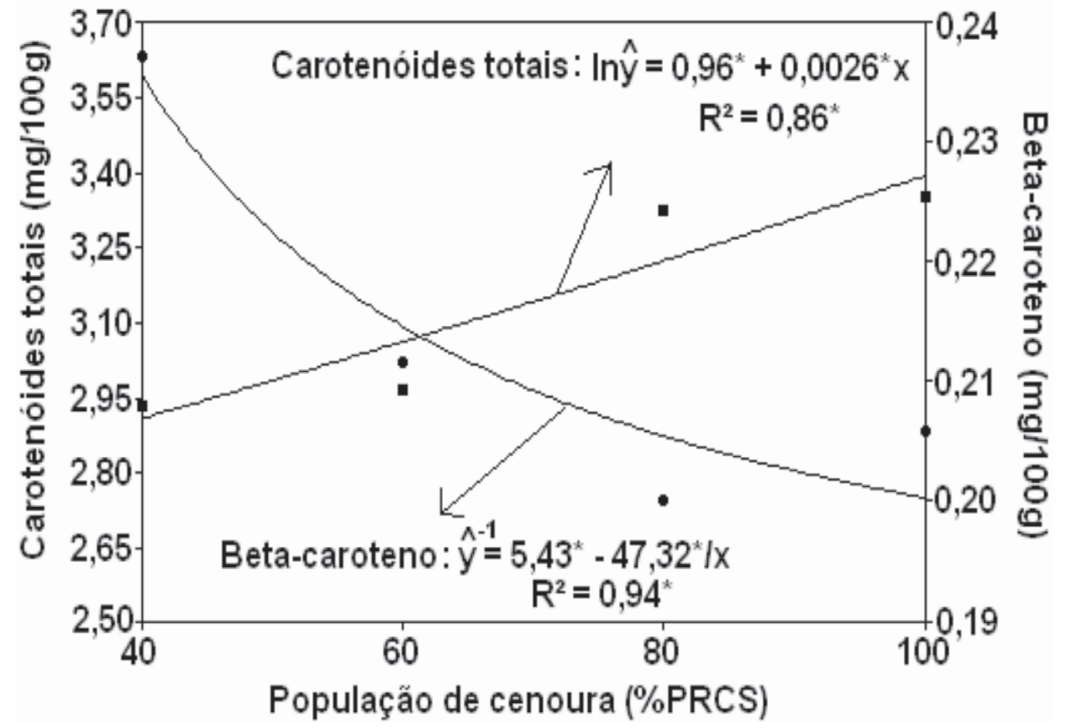

Figura 1. Firmeza, vitamina $C$, carotenóides totais e beta-caroteno de raízes de cenoura em função das densidades populacionais relativas aos cultivos solteiros (PRCS) de cenoura, em sistema consorciado. Mossoró-RN, UFERSA, 2003.

caroteno foi mensurado segundo Moretti et al. (2003).

Realizou-se análise de variância univariada para o delineamento de blocos casualizados em esquema fatorial para avaliar as características de raízes da cenoura e das plantas de alface, através do software SPSS/PC (Norusis, 1990). Os efeitos dos fatores densidades populacionais foram avaliados pelos procedimentos de ajustamento de curvas de resposta através do software 'Table Curve Package' (Jandel Scientific, 1991). face. Este comportamento se deve ao curto período de convívio entre as hortaliças nas diferentes associações de densidades, o que se traduziu em eficiência na avaliação das características de ambas as culturas, pelo fato de não interagir. Por outro lado, para cada uma das características avaliadas, testou-se um ajustamento de curva de regressão simples em função das densidades populacionais de cada cultura componente (Figuras 1 e 2).

\section{Cultura da cenoura}

Nenhuma função de resposta foi obtida para as características de cenoura em função do aumento da população de alface (Figuras 1A e 1B). Os valores médios para firmeza, vitamina $\mathrm{C}$, carotenóides totais e beta-caroteno na raiz de cenoura foram respectivamente: $104,5 \mathrm{~N} ; 13,7 \mathrm{mg} / 100 \mathrm{~g} ; 3,00 \mathrm{mg} / 100 \mathrm{~g}$ e $0,22 \mathrm{mg} / 100 \mathrm{~g}$. Estes resultados demonstram que o período em que as culturas conviveram não permitiu qualquer influência significativa da alface sobre a cenoura. Esta ausência de influência pode ser benéfica na manutenção da qualidade nutricional nos diversos consórcios provenientes das diferentes associações de densidades das culturas componentes.

A firmeza das raízes e o teor de vitamina $\mathrm{C}$ decresceram com o aumento da densidade populacional da cenoura (Figura 1A), passando de $104,8 \mathrm{~N}$ e de 14,9 $\mathrm{mg} / 100 \mathrm{~g}$ na densidade de $40 \%$ da PRCS para $101,8 \mathrm{~N}$ e $13,4 \mathrm{mg} / 100 \mathrm{~g}$ na densidade de $100 \%$ da PRCS, respectivamente. Este aumento da população de cenoura produziu raízes de cenoura mais delgadas com menor firmeza, decorrente principalmente da competição intraespecifica. Já o decréscimo no conteúdo de vitamina $\mathrm{C}$ pode estar relacionado a maior intensidade de autosombreamento das plantas de cenoura, devido ao aumento na sua densidade, conseqüentemente menor fotossíntese líquida, uma vez que o ácido ascórbico tem como precursor a glicose (Taiz \& Zeiger, 2003).

O teor de carotenóides totais aumentou e o de beta-caroteno decresceu com o incremento da densidade populacional da cenoura, passando de 2,90 e de 0,235 $\mathrm{mg} / 100 \mathrm{~g}$ na densidade de $40 \%$ da PRCS para 3,39 e 0,202 $\mathrm{mg} / 100 \mathrm{~g}$ na densida- 
de de $100 \%$ da PRCS, respectivamente (Figura 1B). Este comportamento dos carotenóides totais não concorda com os relatados por Carvalho et al. (2003), que trabalhando no planalto central com duas cultivares de cenoura (Nantes e Alvorada) em densidades populacionais que variaram de 700.000 a 1.000 .000 de plantas por hectare em cultivo solteiro, não encontraram influência do aumento da densidade populacional da cenoura na quantidade de carotenóides totais. No trabalho em foco, as densidades populacionais de cenoura utilizadas variaram de 200.000 a 500.000 plantas por hectare. Esta discordância de comportamento no conteúdo de carotenóides deve-se as condições climáticas e o local de produção, que são completamente diferentes. O conteúdo de carotenóides em cenoura varia com o estádio de desenvolvimento da raiz (Henonen, 1990), clima e local de produção (Gross, 1991). A redução no conteúdo de beta-caroteno decorrente do aumento na densidade populacional da cenoura pode estar relacionada com o autosombreamento das plantas desta hortaliça.

\section{Cultura da alface}

Não se encontrou, também, nenhuma função de resposta para as características de alface em função do aumento da população de cenoura (Figuras 2A e $2 \mathrm{~B}$ ). Os valores médios para firmeza, vitamina $\mathrm{C}$, carotenóides totais e clorofila total nas folhas de alface foram, respectivamente, $27,6 \mathrm{~N} ; 25,7 \mathrm{mg} / 100 \mathrm{~g}$; $696,4 \mathrm{mg} / 100 \mathrm{~g}$ e $1264,7 \mathrm{mg} / 100 \mathrm{~g}$. Este resultado corrobora com o fato de que o curto período de convívio entre as culturas não permitiu influência significativa da cenoura sobre a alface.

Observou-se crescimento da firmeza das folhas de alface com o aumento da sua população (Figura 2A). Constatou-se incremento de aproximadamente 2,5 $\mathrm{N}$ quando a densidade de alface passou de 40 para $100 \%$ da PRCS, correspondendo a um aumento de quase $10 \%$ de firmeza. Este aumento na firmeza das folhas se deve ao crescimento das plantas de alface, ficando as plantas em pé, com folhas mais finas e mais firmes, alongadas e não crocantes.

$\mathrm{O}$ teor de vitamina $\mathrm{C}$ decresceu em função do aumento populacional de al-
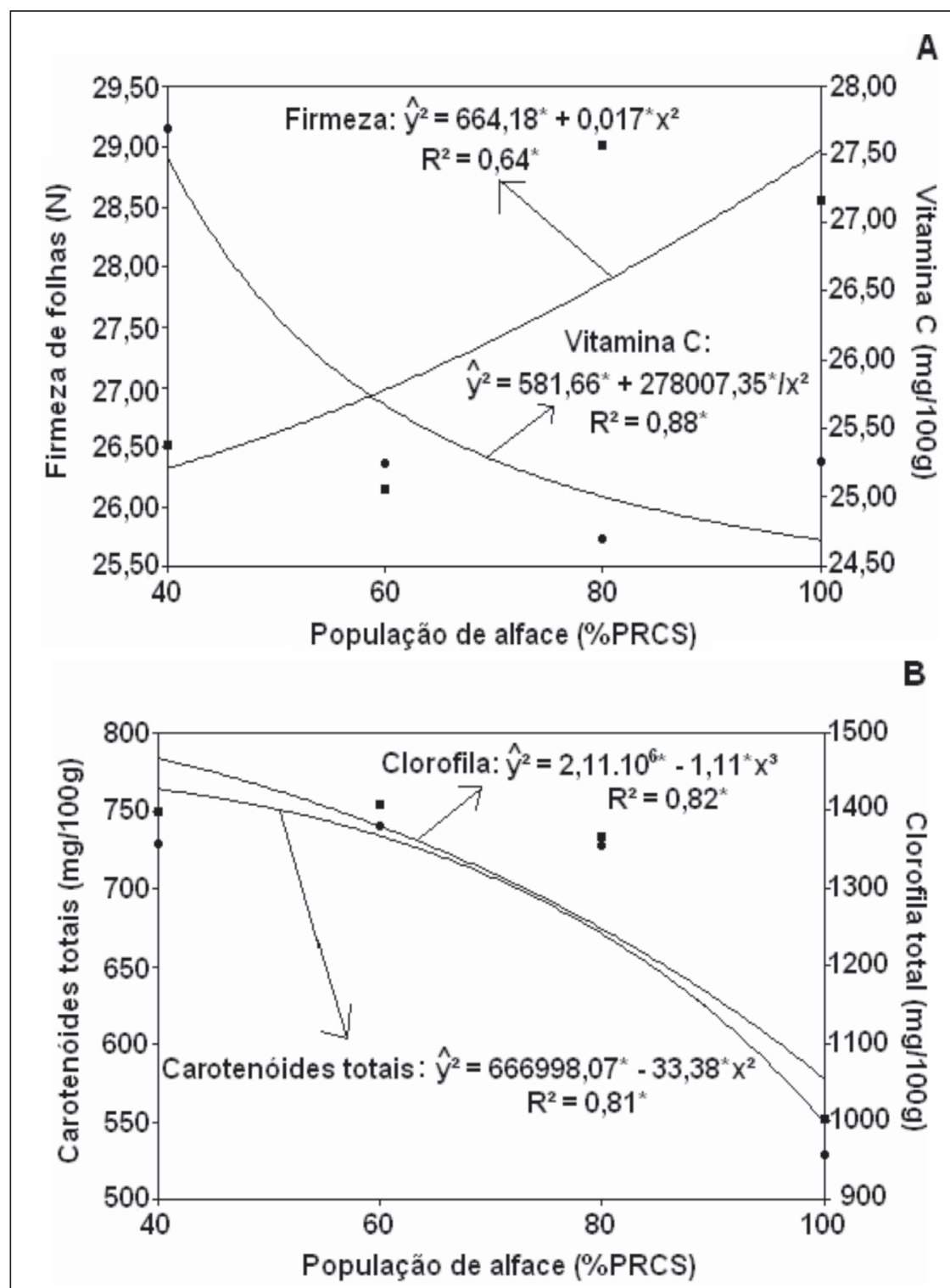

Figura 2. Firmeza, vitamina C, carotenóides totais e clorofila total de folhas de alface em função das densidades populacionais relativas aos cultivos solteiros (PRCS) de alface, em sistema consorciado. Mossoró-RN, UFERSA, 2003.

face (Figura 2A). A redução foi acentuada até a densidade de $70 \%$, sendo menos evidente a partir desse ponto. A diminuição do teor de vitamina $\mathrm{C}$ de $40 \%$ para $100 \%$ da PRCS foi de aproximadamente $12 \%$. Este decréscimo está relacionado a menor quantidade de luminosidade recebida pelas maiores populações de alface, consequentemente menor material de reserva e conteúdo de vitamina C. Para o teor de carotenóides totais constatou-se comportamento oposto àquele observado para a firmeza da folha (Figura 2B), sendo quase de $37 \%$ a diferença de valores nas populações de $40 \%$ e $100 \%$ de alface.
Também, verificou-se redução de aproximadamente $40 \%$ no teor de clorofila total em função do aumento populacional (Figura 2B). Esta redução no teor de clorofila total e de carotenóides, com o aumento da população de alface, pode ter ocorrido devido à competição por luz, induzindo, conforme já mencionado, ao desenvolvimento de plantas com folhas finas, alongadas e firmes. Tal comportamento, provavelmente, culminou num menor metabolismo, com menor acúmulo de vitamina $\mathrm{C}$.

Por fim, pode-se observar que as associações de densidades 
populacionais de cenoura e alface não afetaram qualquer característica de ambas as culturas. Porém, as densidades populacionais da cenoura influenciaram as características da cenoura, e as densidades de alface afetaram as características da folha de alface. A firme$\mathrm{za}$, conteúdo de vitamina $\mathrm{C}$ e de betacaroteno nas raízes da cenoura diminuíram com o aumento da densidade deste cultivo, enquanto que o conteúdo de carotenóides totais aumentou com o incremento na densidade populacional deste cultura. Mesmo comportamento decrescente também foi observado no conteúdo de vitamina $\mathrm{C}$, carotenóides totais e de clorofila total nas folhas de alface. A firmeza das folhas aumentou com o aumento na densidade populacional desta cultura.

\section{REFERÊNCIAS}

AGRIDATA. 2004. Sistema de Informações do Agronegócio de Minas Gerais. Importância das hortaliças. 2004. Disponível em http:// www.agridata.mg.gov.br. Acessado em 29 de outubro 2004.

BAARDSETH P; ROSENFELD HJ; SUNDT WT; SKREDE G; LEA P; SLINDE E. 1995. Evaluation of carrot varieties for production of deep-fried carrot chips. I. Chemical aspects. Food Research International 28: 195-200.

CARVALHO PB de; MACHADO CMM; VIEIRA JV; SILVA JBC da. 2003. Influência da densidade de plantas no teor de carotenóides totais das cultivares de cenoura Nantes e Alvorada. Horticultura Brasileira 21: Suplemento $\mathrm{CD}$. Trabalho apresentado no $43^{\circ}$ Congresso Brasileiro de Olericultura, 2003.
COLLINS ANNE. 2004. Lettuce. In: AC diet food and nutrition. 2004. Disponível em http:// www.annecollins.com/dietnutrition/lettuce. Acessado em 29 outubro 2004

GALANTE A. 2004, 29 de outubro. Os fitoquímicos. In: Nutrição é saúde. Folha Online. Março de 2003. Disponível em http:// www 1.folha.uol.com.br/folha/colunas/ nutricaoesaude.

GROSS J. 1991. Pigments in vegetables: chlorophylls and carotenoids. New York: Van Nostrand Reinhold Company Inc.

HENONEN MI. 1990. Carotenoids and provitamin A activity of carrot (Daucus carota L) cultivars. Journal of Agriculture and Food Chemistry 38: 609-612.

HOLSMEISTER LA. 2004, 29 de outubro. Vegetables. Diabetes self-management, Boulder, CO, Julho0/Augosto 2003. Disponível em http:// www.diabetesselfmanagement.com/ article.cfm?aid=1551 \&sid=3\&sk= 5WZA.

IPA-Empresa Pernambucana de Pesquisa Agropecuária. 1998. Recomendações de adubação para o estado de Pernambuco: 2 a aproximação. $2^{\mathrm{a}}$. ed. Ver. Recife: IPA. 198p.

JANDEL SCIENTIFIC. 1991. Table curve: curve fitting software. Corte Madera, CA: Jandel Scientific. 280p.

LICHTENTHALER HK. 1987. Chlorophylls and carotenoids: pigments of photosynthetic biomembranes. In: PACKER L, DOUCE R (eds) Methods in Enzimology. London: Academic Press. 148: 350-381.

MACHADO CMM; CARVALHO PGB; VIEIRA JV; SILVA JBC da. 2003. Influência do espaçamento na quantidade de açúcares e sólidos solúveis totais em cenoura. Horticultura Brasileira 21: 2 Suplemento 2. CD-ROM. Trabalho apresentado no $43^{\circ}$ Congresso Brasileiro de Olericultura, 2003.

MANGELS AR; HOLDEN JM; BEECHER GR; FORMAN MR. LANZA E. 1993. Carotenoid content of fruits and vegetables: an evaluation of analytic data. Journal of the American Dietetic Association 93: 284-296.
MAZZA G. 1989. Carrots. In: ESKIN NAM (ed). Quality and preservation of vegetables. Boca Raton, FL: CRC Press. p. 76-119.

MORETTI CL; BERG FL das N; MATTOS LM; SAMINÊZ T C de O; RESENDE FV. 2003. Caracterização pós-colheita de cenouras cultivadas em sistema orgânico. Horticultura Brasileira 21: 2 Suplemento 2. CD-ROM. Trabalho apresentado no $43^{\circ}$ Congresso Brasileiro de Olericultura, 2003.

NORUSIS MJ. 1990. SPSS/PC Statistics. Illinois: SPSS Inc. 320p.

OLIVEIRA AM. 2003. Bicultivo de alfaces americanas consorciadas com cenoura em dois sistemas de cultivos em faixas. Mossoró: ESAM. 76p. (Tese Mestrado).

PLANETA ORGÂNICO. 2004. Plantas companheiras. Disponível em http://www. Planeta organico.com.br.

SEMENTES SAKAMA. 2002. Características de cultivares de alface. São Paulo: Sementes Sakama. 2p. (Mimeografado).

SILVA VF da. 1999. Cultivares de alface em diferentes espaçamentos sob temperatura e luminosidade elevadas na região de Mossoró$R N$. Mossoró: ESAM. 25p. (Tese Mestrado).

SIMON PW; WOLFF XY. 1987. Carotenes in typical and dark orange carrots. Journal of Agriculture and Food Chemistry Columbus 35: 1017-1022.

SIQUEIRA GAS. 1995. Espaçamentos de plantio na produção de cenoura "Brasília", no município de Mossoró-RN. Mossoró: ESAM. 23p. (Monografia graduação em agronomia).

TAIZ L; ZEIGER E. 2003. Fisiologia Vegetal. 3 ed. São Paulo: Artmed. 720p.

VIEIRA JV; VECCHIA PTD; IKUTA H. 1983. Cenoura Brasília. Horticultura Brasileira 1: 42.

WORLD CARROT MUSEUM. 2004. Discover the power of carrots. Disponível em http:// www. carrotmuseum.com.br. Acessado em 29 de outubro 2004 